\title{
Research on Music Spectrum Teaching in Junior High School
}

\section{Mo Meng}

\author{
Baoding the Third Middle School branch campus, Baoding071000, China \\ Mmo1215@126.com
}

Keywords: Junior high school music; Read music ability; Teaching research

\begin{abstract}
Music class is a required course in junior high school education. Read music is an essential tool for students to learn music. The effect of read music teaching will directly affect the students' music quality. This article through the questionnaire survey of Baoding city middle school students understand the spectrum of ability to conduct the investigation and study, proposed to improve and enhance the general suggestions and Strategies of teaching ability of spectrum.
\end{abstract}

\section{Introduction}

The outline of the national medium and long term educational reform and development program (2010-2020 years) points out: Moral education should be emphasized in the development of students in basic education, To Stimulate their interest in learning and cultivate their healthy physique and make them develop good study habits. The comprehensive quality of students needs to be improved in an all-round way to achieve balanced development of teaching. Music classroom teaching can improve the students' music quality and accomplishment and strengthen the music classroom education can improve the overall quality of students more comprehensively. Compulsory education music curriculum standard (2011 Edition) also has a clear requirement that the spectrum should be closely linked with singing, playing, creation, appreciation and other teaching content, taking music as the carrier, on the basis of students' perceptual accumulation and cognition, to carry out the teaching of spectrum recognition. Reading music can be learned by the songs or music most familiar to students, and can also be learned with instrumental music. The main forms of current music in China and read music notation, the school can choose two kinds of music form according to the actual situation in the teaching process. With the sol FA in the teaching staff. The compulsory education music curriculum standard of teaching content knowledge spectrum, teaching methods and teaching effect also makes detailed description.

Music class is a required course in junior high school education. Read music is an essential tool for students to learn music. The effect of read music teaching will directly affect the students' music quality. There are a lot of teaching forms in the music class such as appreciation, singing, playing, writing, reading teaching. Among them, the knowledge spectrum is an important tool of learning music, it is a necessary basis for appreciation, singing, playing, writing teaching, has important significance in music education. The student existing knowledge spectrum competence is the foundation of knowledge teaching, based on the knowledge spectrum ability of junior middle school students, the general suggestions and Strategies of teaching ability of spectrum will be proposed.

The grade one in junior middle school was Chosen to conductea questionnaire survey. In order to ensure real, The investigation was anonymous directly to the student questionnaire and test. The questionnaire issued a total of 572, received 572 questionnaires, 558 valid questionnaires.

\section{Investigation on Students' Ability of Spectrum Identification}

\section{Research on Status of Primary School Music Class Learning Music Stave.}

$47.3 \%$ of the students have learning music stave in primary school. The staff learned of these students in primary school music class, always exercise accounted for $2.3 \%$, Regular exercise accounted for $9.1 \%$, less frequent practice accounted for $27.3 \%$, occasional practice accounted for $38.6 \%$, never practice accounted for $22.7 \%$.

Thus it can be seen not all music lessons are in accordance with the curriculum standards and 
curriculum teaching, primary school music class had less than half the staff notation teaching, often training also minority. The current situation of the teaching, students up to junior high school, in the process of music learning difficulties, teachers will have a certain the degree of difficulty.

\section{A Survey of Students Participating in off Campus Training.}

A survey of students participating in off campus training, The results are shown in Figure 1.

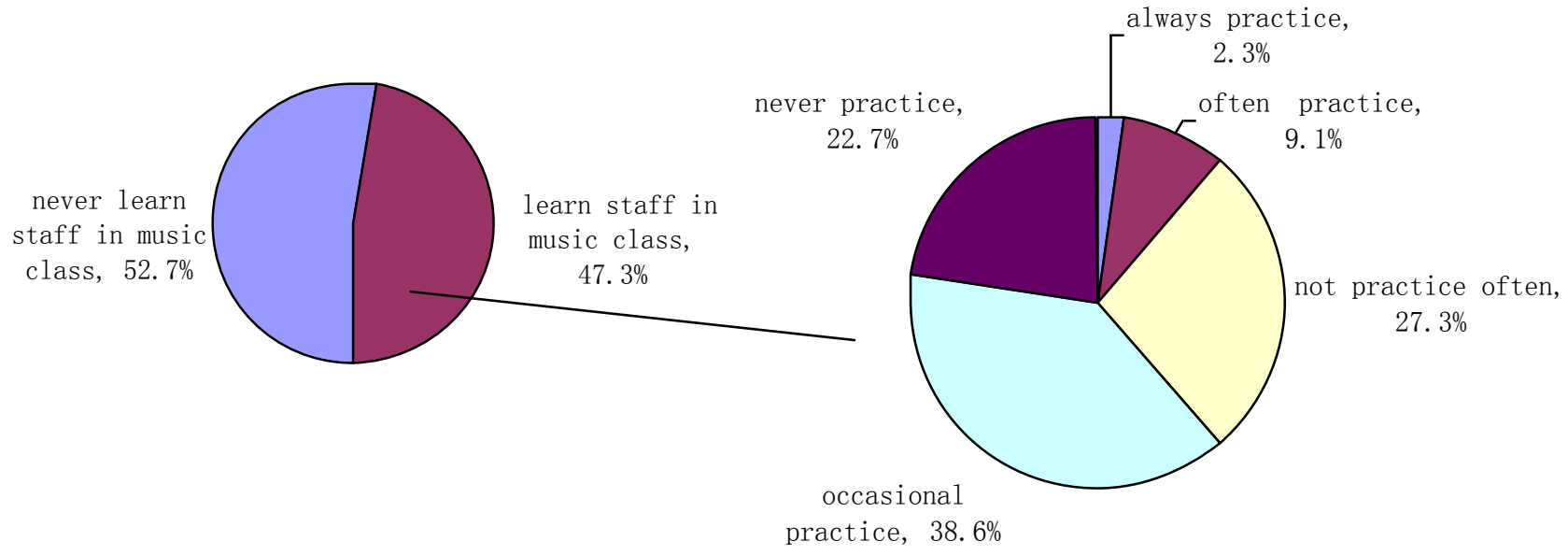

Fig 1. The survey of students participating in off campus training

Among all the students, $35.5 \%$ of them participated in the training. did not participate in the training of the students accounted for $64.5 \%$. which participated in the training of students, learning keyboard accounted for $24.2 \%$, learned western orchestral music for $27.3 \%, 21.2 \%$ of the students studied folk music, accounting for the study of vocal music $9.1 \%$, learn percussion students accounted for $6.1 \%$, other categories accounted for $9.1 \%$.

\section{The Investigation on the Students Understanding of the Clef.}

The investigation on the students understanding of the clef. The results are shown in Fig 2.

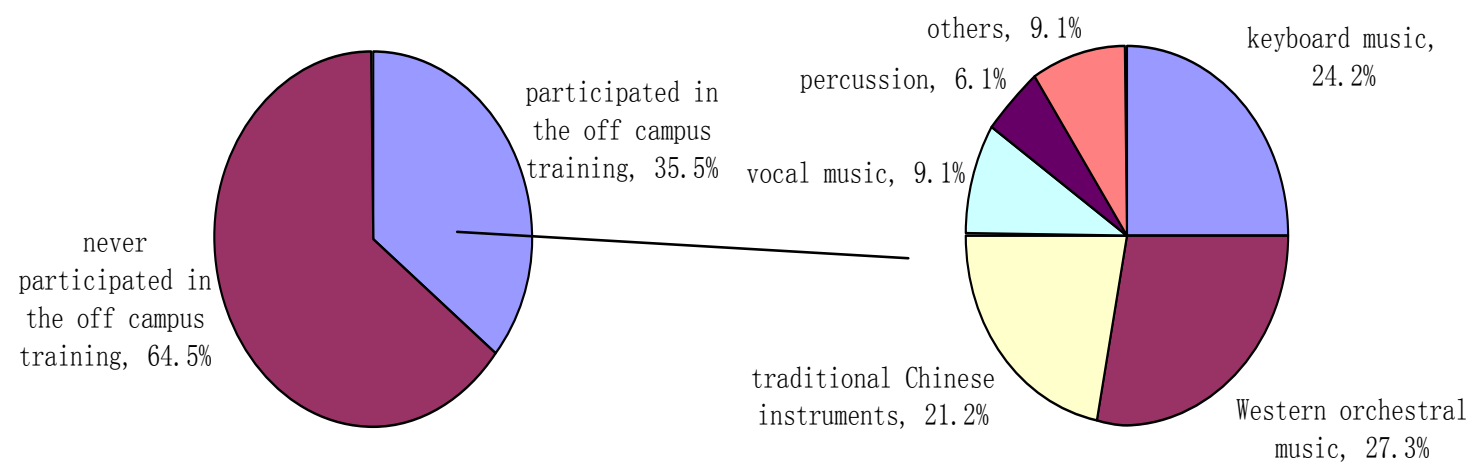

Fig 2. The investigation on the students understanding of the clef.

In the absence of a case. Alone gives the student $\mathrm{G}$ clef. The problem of the test is more professional, strictly speaking can not directly answer the treble clef, but no more than the correct 
answer. $27.9 \%$ of students answered the treble clef. The number of students who answered no answer accounted for $2.2 \%$. $61.3 \%$ of the students did not answer. The number of students who answered incorrectly accounted for $8.6 \%$.

$\mathrm{G}$ clef which is the highest utilization rate waw chosen to investigate. It often appears on objects as decorative patterns. Nearly $70 \%$ of the students did not know its name. It shouldn't have happened, Therefore, it is an important teaching content to strengthen the teaching of students' spectrum recognition

\section{Examine Students for Knowledge of the Relationship between Different Note Time Values.}

The correct students accounted for $15.1 \%$ of the total number of students in this question. $67.7 \%$ of the students didn't know the answer, $17.2 \%$ students are wrong. The staff had never learned the extracurricular class do not answer the correct answer; music lessons learned but not on extracurricular class the correct rate is $8 \%$; the correct rate on the extracurricular class for $36.4 \%$.

This problem is a direct reference to the staff notes the knowledge, the correct rate is $15.1 \%$. Obviously, to really grasp the staff accounted for only about $15.1 \%$.

Test Students on the Pitch Position on the Staff.

This question, $22.6 \%$ answered correctly, 9.7\% students answered incorrectly, $67.7 \%$ of the students don't know the answer. Which is not learned the staff and had no extracurricular class could not answer the correct answer.

The correct rate of school staff in the music class but not on extracurricular class for $32 \%$. The accuracy rate of students who went to extracurricular classes was $39.4 \%$.

Through sorting out the questionnaire, it was found that several classmates left traces of finding sound on the diagram given by this question. Place the note on the next line, and count the number of lines until you find the given tone. This phenomenon indicates that some students know the distribution of the staff of the pitch, but no master. This explains also is only the staff have the knowledge, the correct rate of the pitch of the note to examine reasons to be higher than the correct rate for the duration of the test rhythm.

In summary, through the analysis of the survey results can be seen in the school music class, teachers pay more attention to the popularity of musical knowledge teaching, the number of exercises in class a lot, but the level of the students is not optimistic. The class of music notation is less than half of the classroom teaching, practice staff notation is very few people. Even the students who study musical instruments, they could not all mastered the knowledge points on the spectrum. The correct rate of investigation involved staff knowledge are not up to the 30\% This shows that students should grasp the lack of knowledge on the spectrum, the students' ability to learn music also have to worry about.

\section{Suggestions for Improving and Improving the Teaching Ability of Spectrum Recognition}

\section{Correct Attitude on Spectrum Teaching.}

Since the promotion of quality education, the music class has gradually been attached importance to by school leaders. The spectrum recognition teaching is the main content of music class.

According to the analysis of the survey results showed that It is very difficult for students to meet the requirements of the music curriculum standards. Improving the students' ability of reading musical notation becomes the primary task of music teaching in junior high school.

This is necessary, through classroom education, extracurricular games, singing competitions, musical instruments and other forms to stimulate students' enthusiasm for learning music. Identification of spectrogram is a necessary way to learn music. The role of music score in music learning is equivalent to the role of text in books. Students are fully aware of the importance of learning spectrum, from passive learning to active learning, so as to improve the current situation of the teaching of spectrum recognition.

Strengthening Management and Improving the Teaching Level of Teachers.

Teachers play a very important role in teaching and learning, In order to improve the teaching ability of spectrum recognition, first of all, teachers' music quality should be improved, and they 
should set up good teaching ideas and flexible use of foreign excellent education system in the classroom teaching of spectrum recognition. The teachers' music quality will be improved through training during the holiday, participating in academic conferences, teaching observation, preparation methods, and make them have good occupation accomplishment and lofty ideals, and obtaining a wide range of artistic accomplishment. Secondly, the administrative department of education should provide the material conditions for curriculum implementation, increase investment in the underlying hardware, change idea, realize the importance of music education in quality education, and strengthen the management and explore the use of different evaluation methods for teaching evaluation, improve educational administration management level.

\section{References}

[1] KathleenScott Bennetts.Boys' music School context and middle-school boys' musical choices[J].Music Education Research, 2013, 15 (2): 214-230

[2] Jin Wang.Discussion on Primary School Music Teaching: How to Increase Students' Enthusiasm for Learning Music[J].Cross-Cultural Communication, 2015,11 (5):23-26.

[3] Giebelhausen Robin.In the Beginning of the Middle[J].General Music Today, 2015,29 (1): 41-45

[4] Dr. John L. Vitale. "Let them Jam!" Incorporating Unschooling Pedagogy in the Secondary School Music Classroom[J].Journal of Unschooling and Alternative Learning, 2008, 2 (3), pp. 28

[5] Han Min. The application of interesting teaching in junior high school music teaching [J]. Diary of teenagers (education and Teaching Research), 2015,05:25.

[6] Xiang Yan. The application of project teaching method in music teaching in junior high school [J]. times education, 2013,14:178.

[7] Xue Jiao. The exploration of interactive teaching mode in junior high school music class [J]. New curriculum guidance, 2012,34:27.

[8] Guan Ling. Art of classroom regulation in the teaching of music appreciation in senior high school [J]. new curriculum (Part Two), 2016, (7): 64

[9] Feng Tianbo. Problem analysis and optimization of teaching reform in [J].. Drama House, 2015, (05): $179+187$.

[10] he Lili. Classroom control - let the classroom live and not chaos [J]. Gansu education, 2016,0 (A): 55 .

About Author: Mo Meng, 1991. 12, Master, Teacher 